impracticable, and it was deemed the more prudent course to excise it, in carrying out which measure a part of the bone was found in a comminuted condition.

W. P-, aged forty, a tailor residing at Holloway, was admitted on the night of Sunday, Oct. 30th, with a dislocation of the astragalus of the right foot forwards and outwards. He says that some two hours previous, whilst walking in the fields in his neighbourhood, it being very dark, he stumbled into a dry ditch about two feet in depth, his foot twisting under him.

When admitted, the ankle appeared much distorted, the foot being inverted, and its outer side resting on the ground. The outer malleolus was very prominent, and the skin over it extremely tense. Immediately in front of this, and nearly on the same level, was a hard projecting surface, apparently smooth and rounded at its margin-being indeed, to all appearance, the navicular articulating surface of the astragalus, the long axis of which was placed transversely, instead of being in its natural oblique position. This portion of the astragalus--its head-seemed to rest on the calcaneum and cubrid bones at their junction; the skin over this part was very tightly stretched and already discoloured. The upper articulating surface of the bone could be distinctly felt internal to and beneath the external malleolus. The internal malleolus could not be disinguished, being, as it were, hidden in the soft parts forming the inner side of the foot. The arch of the foot was partially lost, and the length of the heel diminished. It seemed, therefore, not to be a mere dislocation of the bone forwards and outwards, but that, in addition, the astragalus was twisted on its own long axis.

Chloroform was administered, and reduction attempted, but in vain. After a consultation with his colleagues, Mr. Canton excised the astragalus by making a horseshoe incision, commencing just above the outer malleolus, carrying it forwards around the projecting head of the astragalus, and terminating beneath the same malleolus. Reflecting this flap, the bare head of the bone was seen projecting; it was seized, the adhering ligamentous structures carefully dissected away, and the entire bone removed. It was then found that a portion of the posterior and internal angle was broken off and remained in a comminuted state, still adherent to the internal lateral ligament of the joint; the inferior margin of the head was also somewhat bruised. The edges of the wound being brought together, an iron splint with a foot-piece was adjusted, and the patient removed to bed.

The case has progressed favourably up to the present time, and it is expected that a good recovery will ensue.

\section{ST. MARY'S HOSPITAL.}

CAULIFLOWER EXCRESCENCE OF THE OS UTERI ; REMOVAL BY THE WIRE-ROPE ECRASWUR; CLINTCAI REMARKS.

(Under the care of Dr. Graily Hewirt.)

THE subject of this case, E. R-, aged thirty-three, was admitted on the 13th August, 1863. She was married, and had had three children-the youngest eight years previously. The catamenia had been regular up to four months before admission, since which time there had been an almost constant but slight escape of fluid, more or less tinged with blood, from the vagina. When not tinged with blood the discharge was brownish. Occasionally a profuse watery discharge was observed. She had for some months previously failed rapidly in bealth; the complexion was pale and the expression anxious; and she had sensibly lost flesh. There were frequent pains in the pelvic region.

On examination, the upper part of the vagina was found occupied by a mass as large as a hen's egg, attached to and continuous with the os uteri. Above the tumour the cervix nteri was found not considerably increased in thickness, and the uterus itself not increased in size. The mass was soft and spongy in texture, conveying such an impression as would be produced by a piece of sponge, in the substance of which were embedded large-sized shot. It bled when touched, but was not sensitive. Dr. Graily Hewitt decided on removing the tumour, Mr. Lane, sen., who saw the case with him, concurring in the propriety of an operation. Prior to this, however, the patient's strength and condition generally were recruited by liberal diet, bark, port wine, \&c.

On September 27 th she had much improved in health, and the operation was forthwith performed. The tumour was re- moved by cutting through the cervix uteri, immediately above the tumour, by the wire-rope écraseur constructed by Dr. Hicks. The immediate result of this operation was very satisfactory, and on October 7 th she left the hospital exceedingly benefited in every respect.

In the course of his clinical remarks to the class on the foregoing case, Dr. Graily Hewitt observed that there were comparatively few cases of cauliflower excrescence of the os uteri which admitted of operation, it being too frequent an occur. rence that either the body of the uterus is implicated by extension of the disease (which is of a cancerous nature) to that part of the organ, or that the cervix is not found sufficiently healthy to warrant the belief that all the diseased mass can be conveniently removed. In this case, however, the circumstances were all very favourable for operation : the body of the uterus apparently sound, the neck of the tamour also unaffected, and the diameter of the part to be cut through small. He believed that the removal of the growth was beneficial to the patient, even supposing that the uterus higher up eventually became the seat of cancerous disease, the patient being saved the profuse debilitating loss attending the ulceration of the growth while in process of disintegration. Further, aithough the probabilities were against complete recovery in such a case as the foregoing, the patient at all events was given the benefit of the doubt, and as far as possible placed under favourable conditions for recovery. An extremely liberal diet should always be adopted in these cases, and the further progress of the disease would be best averted or postponed by attention to this. The change effected in the appearance of the patient during her two months' subjection to a nourishing and supporting diet was very great.

With reference to the operation itself, Dr. Graily Hewitt remarked that the instrument used was a very convenient one, the flexibility of the rope admitting of its easy adjustment. The rope was, however, liable to break, and hence differentsized ropes should be kept ready. The rope first used in this case, with twenty strands of wire, broke. A second rope, with twenty-five strands of wire, cut through the cervix readily.

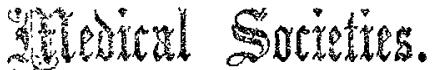

\section{MEDICAI SOCIETY OF LONDON. NoVEMBER 21sT, 1864}

Dr. Greenhalgit, President, in the chair.

ON DIFEERENT MODES BY WHICH CONSTITUTIONAL SYPHILIS MAY BE COMMUNICATED.

BY HENRY LEE, ESQ., F.R.C.S.

UNwL within a comparatively short period, the author observed, it was of late years a well-nigh universally received opinion in Europe, that syphilis could only be communicated by a primary syphilitic sore; that a chancre which was followed by secondary symptoms was always the result of contact with the secretion of a similar affection. Great and grievous have been the injuries inflicted by this theory both on single and on married persons. For anyone who in any way had contracted. syphilis under the reign of this cruel dogma, was pointed at with the finger of scorn, was accused of having necessarily contracted the disease in some illicit way, and was not unfrequently most unjustly excluded from society. More than this: Cases not unfrequently occurred, and have occurred under the author's own observation, where legal proceedings have been threatened or actually carried into execution, in consequence of a person havirg, as was supposed, contracted fresh disease after marriage, the parties instituting the proceedings being misled by the doctrine which then prevailed. The following case was given in illustration :-A gentleman who had had syphilis married. A few months afterwards his wife was found to have some indurated tubercles about the labia, with corresponding enlargement of the inguinal glands. A secondary eruption followed. The friends of the lady ascertained the nature of the disease, and being instructed according to the prevailing theory, accused the husband of having been unfaithful after his marriage. In this stage of the case the question was put to the author, "Can the husband have given the disease to his wife without himself having had a primary chancre?" Mr. Lee was enabled here entirely to clear the husband's character as far as his conduct subsequent to his marriage was concerned. 